\title{
Al/Robotics and the Poor
}

\author{
Joachim von Braun and Heike Baumüller
}

\section{Contents}

Introduction

A Framework of AI/Robotics Impacts on the Poor and Marginalized $\ldots \ldots \ldots \ldots \ldots \ldots \ldots \ldots$

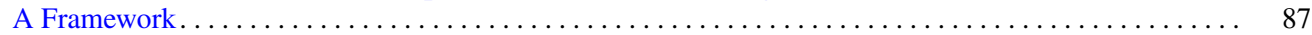

Opportunities of Data and Information Systems about Poverty $\ldots \ldots \ldots \ldots \ldots \ldots \ldots \ldots \ldots \ldots . \quad 88$

Education and Knowledge Links with AI/Robotics $\ldots \ldots \ldots \ldots \ldots \ldots \ldots \ldots \ldots \ldots \ldots \ldots$

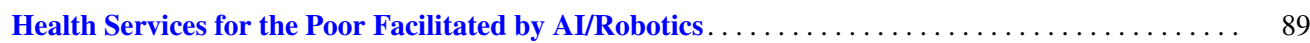

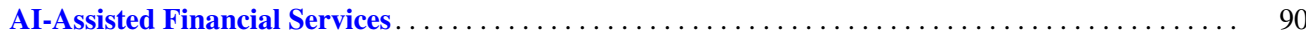

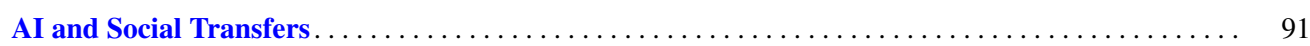

AI/Robotics Effects for the Poor in Employment, Small Business, and Smallholder Farming . . . . 91

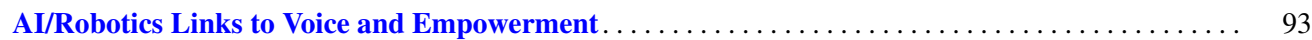

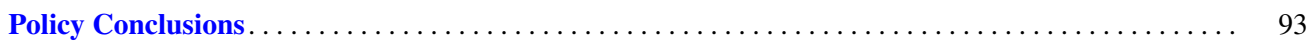

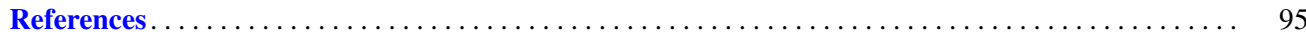

\section{Abstract}

Artificial intelligence and robotics (AI/R) have the potential to greatly change livelihoods. Information on how $\mathrm{AI} / \mathrm{R}$ may affect the poor is scarce. This chapter aims to address this gap in research. A framework is established that depicts poverty and marginality conditions of health, education, public services, work, small businesses, including farming, as well as the voice and empowerment of the poor. This framework identifies points of entry of $\mathrm{AI} / \mathrm{R}$, and is complemented by a more detailed discussion of the way in which changes through $\mathrm{AI} / \mathrm{R}$ in these areas may relate positively or negatively to the livelihood of

J. von Braun $(\bowtie) \cdot H$. Baumüller

Center for Development Research (ZEF) Bonn University, Bonn,

Germany

e-mail: jvonbraun@uni-bonn.de; hbaumueller@uni-bonn.de the poor. Context will play an important role determining the $\mathrm{AI} / \mathrm{R}$ consequences for the diverse populations in poverty and marginalized populations at risk. This chapter calls for empirical scenarios and modelling analyses to better understand the different components in the emerging technological and institutional AI/R innovations and to identify how they will shape the livelihoods of poor households and communities.

\section{Keywords}

Poverty $\cdot$ Inequality $\cdot$ Artificial intelligence $\cdot$ Robotics $\cdot$ Research and development $\cdot$ Marginalization 


\section{Introduction ${ }^{1}$}

Artificial intelligence based on the utilization of big data, machine learning, and applications in robot technologies will have far-reaching implications for economies, the fabric of society and culture. It can be expected that artificial intelligence and robotics (AI/R) offer opportunities but also have adverse effects for the poor segments of societies and that the effects will differ for specific applications of AI/R. The implications of $\mathrm{AI} / \mathrm{R}$ for poverty and marginalization are, to date, not much studied, but are important for ethical considerations and $\mathrm{AI} / \mathrm{R}$ related policies. It actually seems that attention to robots' rights is overrated whereas attention to implications of robotics and AI for the poorer segments of societies are underrated. Opportunities and risks of $\mathrm{AI} /$ robotics for sustainable development and for welfare of people need more attention in research and in policy (Birhane and van Dijk 2020).

In order to derive potential implications for the poor, a theoretical framework is needed that captures the structural and dynamic factors shaping incomes and livelihood capabilities of the poor without $\mathrm{AI} / \mathrm{R}$ and that identifies points of entry of $\mathrm{AI} / \mathrm{R}$ as well as their impact on poor households and communities. For this reason, a framework of opportunities and risks for conceptualizing this review is outlined in A Framework of $\mathrm{AI} /$ Robotics Impacts on the Poor and Marginalized section.

There are several caveats to such framing. The field of $\mathrm{AI} / \mathrm{R}$ is developing quickly, bringing about changes of limited predictability. Uncertainties also surround the potentially changing regulatory regimes and policies that will frame $\mathrm{AI} / \mathrm{R}$ innovations and applications. ${ }^{2}$ It is important to also stress that "the poor" are not at all a uniform set of people but that this descriptor denotes a highly diverse group whose composition changes over time. Therefore, the impacts of

\footnotetext{
${ }^{1}$ This paper is based on Joachim von Braun's contribution to the conference on "Robotics, AI, and Humanity: Science, Ethics, and Policy", jointly organized by the Pontifical Academy of Sciences and the Pontifical Academy of Social Sciences, at the Vatican on May 1617, 2019. von Braun's contribution was also published as a ZEF Working Paper (von Braun 2019) and later expanded upon for the purposes of this present publication.

${ }^{2}$ It is important to highlight that access to ICTs supporting infrastructure for the poor (incl. network coverage, speed, costs) is very unequal. The Pontifical Academy of Sciences addressed this issue in a conference: Connectivity as a Human Right, 10 October 2017, Scripta Varia 140, Vatican City, 2018. Further information on costs and connectivity are, for instance, available regarding the network speed by country (SPEEDTEST n.d.), the expansion of the 4G coverage (McKetta 2018), the Price Index (ITU 2019), and further figures on global digitalization (Kemp 2018). Moreover, gender bias has to be kept in mind when reflecting on benefits and challenges of $\mathrm{AI} / \mathrm{R}$ for the poor and marginalized. Research found that women have less access to ICTs, especially in areas with high levels of poverty. Compared to men, women in South Asia are $26 \%$ less likely to own a mobile phone and $70 \%$ less likely to use mobile internet. In Sub-Saharan Africa, the shares are 14\% and 34\%, respectively (GSMA 2018).
}

$\mathrm{AI} / \mathrm{R}$ on diverse groups of the poor will differ. Poverty and inequality effects will also be context-specific across countries, partly depending on infrastructures. AI/R may theoretically reduce poverty while increasing inequality or vice versa.

Key areas particularly relevant for poor people's livelihoods that are likely to be significantly impacted by AI/R in the medium and long term are education, health, financial and public services, employment, small businesses incl.farming, natural resources management, voice and empowerment. These key areas form the structure of this review. In the final section, some policy measures will be discussed that might contribute to poverty reducing and inclusive $\mathrm{AI} / \mathrm{R}$ innovations and applications.

\section{A Framework of Al/Robotics Impacts on the Poor and Marginalized}

There has been significant progress in the reduction of poverty in the developing world over the past few decades. In 1990, 36\% of the world's people lived in poverty (income of less than US $\$ 1.90$ a day in 2011 purchasing power parity (PPP)). By 2015, that share had declined to $10 \%$. The number of people living in extreme poverty stood at 736 million in 2015, indicating a decrease from nearly 2 billion in 1990 (World Bank 2018). This progress is the result of various factors, including economic growth reaching the poor and, in many countries, an increase in attention to social protection policies.

While poverty levels are on the decline at the global level, they remain high in some regions, notably in Sub-Saharan Africa and South Asia where $85 \%$ of the extreme poor live. The World Bank (2018) also warns that the decline may be slowing down. In the case of Sub-Saharan Africa, the absolute numbers are in fact increasing and the region is predicted to host $87 \%$ of the extreme poor by 2030 (World Bank 2018). Therefore, this review of potential AI/R impacts on the poor pays particular attention to Sub-Saharan Africa. At the same time, Sub-Saharan Africa's growing population also brings opportunities. The region already has the world's youngest population, being home to over 250 million young people (aged between 15 and 24 years) ${ }^{3}$ who can learn quickly and adapt to new technologies such as $\mathrm{AI} / \mathrm{R}$.

Being poor is not defined just by lack of income. Access to education, to basic utilities, health care, nutrition, and security are also critical for well-being. ${ }^{4}$ In Sub-Saharan

${ }^{3}$ Data from UN Department of Economic and Social Affairs, downloaded on 10 January 2020. https://population.un.org/wpp/Download/ Standard/Population/

${ }^{4}$ Such a multidimensional view of poverty has been adopted by the World Bank and it is found that, "[a]t the global level, the share of poor according to a multidimensional definition that includes consumption, education, and access to basic infrastructure is approximately 50 percent 


\section{Context: Marginality conditions potentially impacted by $\mathrm{Al} / \mathrm{R}$}

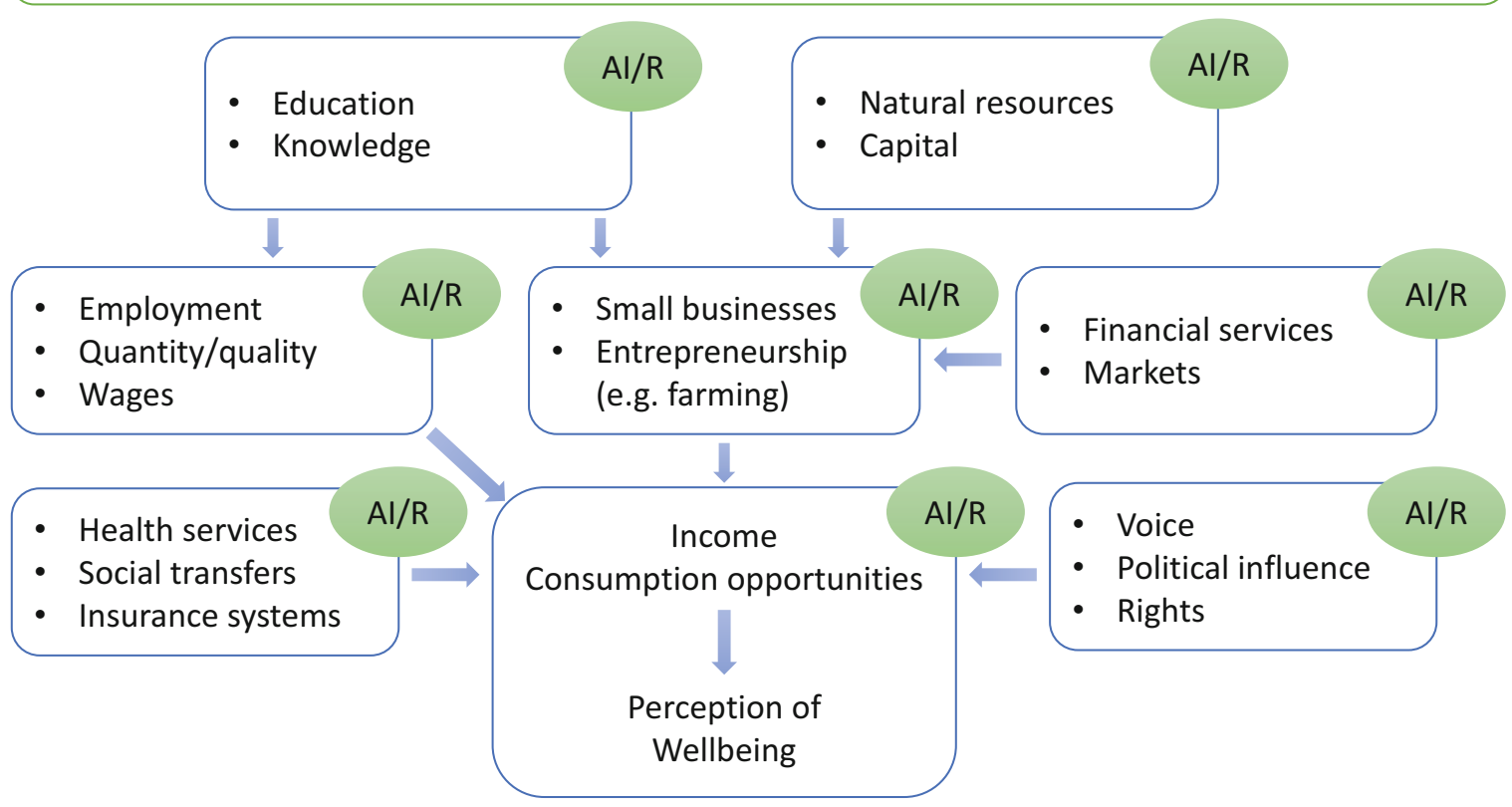

Fig. 1 Framework for assessing the impacts of AI/R on poor people. Source: designed by authors

Africa, low levels of consumption and high levels of food insecurity are often accompanied by challenges in nonmonetary dimensions. Poverty is to a great extent a matter of structural forces such as exclusion, discrimination and the deprivation of rights, governance deficiencies and corruption, and the forces of ecological change that increase the vulnerability of the poor, as many of them depend on natural resources living at the margins in rural areas or in high-risk margins of urban areas. These aspects are captured by the concept of marginality. ${ }^{5}$ Marginality encompasses broader approaches such as relative deprivation and social exclusion or the capabilities approach.

Relative deprivation builds on the idea that the value of objective circumstances depends on subjective comparisons (Stark and Bloom 1985). The relative deprivation concept adds an important dimension to absolute poverty concepts because it involves comparisons with other people. AI/R may change the patterns of comparing one group of people with "others". Such comparisons may include the comparison of people aided by robotics with others not having access to a specific robotics aid, or even a direct comparison of people

higher than when relying solely on monetary poverty" (World Bank 2018, p. 9).

${ }^{5}$ Marginality can be defined as an involuntary position and condition of an individual or group at the edge of social, economic, and ecological systems, preventing the access to resources, assets, services, restraining freedom of choice, preventing the development of capabilities, and causing extreme poverty (von Braun and Gatzweiler 2014). and robots, for instance when robots take on tasks which had previously been carried out by low-income workers. Certainly, AI/R will change patterns of relative deprivation.

\section{A Framework}

Following the above-mentioned framing, Fig. 1 outlines a set of factors influencing poor households and their members' wellbeing. Each of these factors, as well as the forces determining marginality, may be impacted by $\mathrm{AI} / \mathrm{R}$ as depicted within the blocks of Fig. 1. There are many potential points of entry for $\mathrm{AI} / \mathrm{R}$ on the different dimensions of this framework. Naturally, these emerging, disruptive technologies bring both opportunities and risks for poor households.

Walking through the framework shown in Fig. 1, starting in the middle, the influence of employment and small businesses and entrepreneurship, respectively, on the income and consumption opportunities are of significance. Through the introduction of AI/R, mobility costs in general may be reduced and opportunities for mobility may also improve for the poor. Labour tends to be the most important asset of the poor. Thus, employment and small enterprise opportunities have a key influence on income and consumption of poor households.

As a prerequisite for improved access to remunerative employment and business opportunities, education and knowledge are essential for impoverished communities. Improving 
households' education and knowledge base not only affects the quantity and quality of work but also their wages. Furthermore, natural resources and capital play an important role in shaping business opportunities and entrepreneurship. $\mathrm{AI} / \mathrm{R}$ is likely to have deep impacts on these linkages.

Improving poor people's access to services and markets, such as financial, health, and insurance services or social transfers, is another driving factor in increasing and stabilizing poor households' income and consumption opportunities and their wellbeing. AI/R may influence these service sectors and their operations, for instance, by lowering access barriers.

As mentioned above, how (poor) people perceive their situation is heavily influenced by how they view themselves in relation to others, i.e. by how they assess their relative deprivation. By strengthening people's voice and political influence, their perceptions as well as their actual wellbeing can be positively influenced. AI/R contributions could be immense in improving accountability and transparency of governments for their citizens, thus ensuring improved service delivery and empowering local development actors and policy makers.

\section{Opportunities of Data and Information Systems about Poverty}

The lack of reliable data in developing countries is a major obstacle to planning and investment in sustainable development, food security, and disaster relief. Poverty data, for example, is typically scarce, sparse in coverage, and labour-intensive to obtain. Remote-sensing data such as highresolution satellite imagery, on the other hand, is becoming increasingly available and inexpensive. In addition, the growing use of digital technologies is yielding a wide range of incidentally collected data e.g. on the movement of people or spending on airtime. Importantly, many of these analytical tools can provide real-time alerts to take timely actions, including in emergency situations.

An important contribution of AI to poverty reduction is the enhanced capability to identify the poor. Data and innovative machine learning-based identification strategies are already advancing to provide a more up-to-date and welldefined information base compared to traditional household surveys or indicator systems (e.g., Mirza 2018; Zurutuza 2018). For instance, night time lights are substantially correlated with economic wealth. In addition, automated processes can be used to identify the roof material, source of light, and access to water sources - based on satellite images - to derive households' economic situation.

Jean et al. (2016), for instance, demonstrate the usefulness of AI for estimating consumption expenditure and asset wealth from high-resolution satellite imagery. They suggest a learning approach in which night time light intensity is used as a data-rich proxy and a model is trained to predict night time lights from daytime imagery simultaneously with learning features that are useful for poverty prediction. The model applies filters that identify different terrains and structures, including roads, buildings, and farmlands. Using survey and satellite data from five African countries-Nigeria, Tanzania, Uganda, Malawi, and Rwanda-they show that neural networks can be trained to identify image features that can explain up to $75 \%$ of the variation in local-level economic outcomes.

The rapid spread of the mobile phone across the developing world is offering access to a wide range of new data which has already been used for poverty mapping (e.g. Blumenstock and Cadamuro 2015; Smith-Clarke et al. 2014; Soto et al. 2011; Steele et al. 2017). AI-based tools could improve the sophistication of these analyses. For example, Sundsøy et al. (2016) use deep learning to analyse mobile phone datasets in order to classify the socio-economic status of phone users. Data used in the analysis include basic phone usage, top-up pattern, handset type, social network structure and individual mobility. Any use of personal data will have to go hand-inhand with well-developed data protection rules, awareness campaigns and digital literacy training, in particular for the poor and marginalized who may be less informed about associated risks.

Accurately mapping populations through AI can inform pro-poor targeting of e.g. infrastructure, social security, health care or emergency relief. Facebook, for instance, is developing detailed population density maps by using satellite imagery, machine learning algorithms, and population statistics to ensure that connectivity and other infrastructure reaches the entire population even in remote, sparsely populated areas. ${ }^{6}$ The maps can also be used e.g. to facilitate the provision of humanitarian aid or plan health care interventions. The map of Malawi, for instance, was used by local partners to better target a measles and rubella campaign (Bonafilia et al. 2019). Other examples of using AI-assisted data outputs to improve the provision of services to the poor are presented in AI-Assisted Financial Services section.

\section{Education and Knowledge Links with Al/Robotics}

$\mathrm{AI} / \mathrm{R}$ may be of great benefit to the poor to the extent that these technologies enhance their access to education and knowledge, upskill their capabilities in the labour market, and

\footnotetext{
${ }^{6}$ Maps for Africa have already been completed (available at https://data. humdata.org/dataset/highresolutionpopulationdensitymaps) and maps for the rest of the world are expected to be added in the near future (Singh 2019).
} 
increase their income earning capabilities in small businesses and farming. However, education systems tend to directly and indirectly exclude or marginalize the poor: directly through school fees or low quality education in poor communities, and indirectly through a lack of time on the part of the children and other constraints on the part of the parents in poor communities. Time constraints arise for millions of children that work in addition to attending school; when excessive time is spent at work, education suffers and lifetime earnings are reduced as Mussa (2018) shows for cohorts of rural child labourers in Ethiopia. The inequalities tend to grow with levels of education, i.e. secondary and tertiary levels. Girls remain underrepresented in these levels leading to gender gaps (von Braun 2018). Digital literacy constraints may additionally inhibit the acquisition of skills by use of interactive distance learning systems empowered by AI.

There are new opportunities through $\mathrm{AI} / \mathrm{R}$ in education which foster the inclusion of the poor. Du Boulay et al. (2018) argue that AI technologies can assist both educators and learners by providing personalized support for students, offering tools for teachers to increase their awareness, and freeing up time to provide nuanced, individualized support. Nye (2015) reviews intelligent tutoring systems (ITS) targeting the developing world. An interesting example from Kenya is the "Kio Kit" (BRCK n.d.), a fully integrated education platform designed in Kenya which turns a school room into a digital classroom using tablet computers, wireless tablet charging and securing the tablets in a hardened, water-resistant, lockable case. Such education platforms empowered by AI could make a big difference in the future, provided it is made accessible to the poor in marginal rural areas. However, barriers to using ITS need to be addressed, including students' basic computing skills and factors like hardware sharing, mobile-dominant computing, data costs, electrical reliability, internet infrastructure, language, and culture (Nye 2015).

AI-assisted translation and speech recognition may hold great potential for the poor by overcoming barriers of language and illiteracy. Google's speech-to-text service, for instance, uses neural network models to convert audio to text, including several languages spoken by the poor, such as Swahili, Zulu, Cantonese, Mandarin, and several Indian languages (Google Cloud 2019). These technologies could substantially increase access to information and services for disadvantages groups. For now, the data requirements to train machine learning algorithms or neural networks still pose an obstacle to including less commonly spoken languages. However, as more and more written and spoken material is being digitalized and made accessible online, big data analytics will become increasingly efficient and further improve over time.

\section{Health Services for the Poor Facilitated by Al/Robotics}

The poor have difficulties to claim their rights to public services. The health sector is particularly interesting for $A I / R$ applications, given the ongoing digitalization of all types of health data and health information. The long-term potential for advancing the field of digital health and precision and personalized medicine can be immense when AI/R supported medical and public health decision-making reduces costs (Ciechanover 2019). Recognizing this potential, the International Telecommunication Union (ITU 2018) has established a new Focus Group on "Artificial Intelligence for Health" (FG-AI4H) in partnership with the World Health Organization (WHO) to develop standardized assessment frameworks for AI-based health solutions, such as AI-based diagnosis, triage or treatment decisions. Thereby, the group aims at assuring the quality of solutions, fostering their adoption and improving global health. As these developments bring down costs, they may enhance poor people's access to health services. To date, however, these innovations still tend to be far from reaching the poor.

There are clear advantages for worker health from AI/R, for instance when harmful work tasks can be handed over to robots. Pesticide spraying in fields is an important example, including the drone-based detection and mapping of insect infestations at micro level for optimal targeting. A similar safety-enhancing example is the employment of AI technology to improve the safety of mining workers by reducing their intensity of work and exposure to high-risk assignments that could be taken over by robots.

Another important area of application with particular relevance to the poor is the detection and prevention of malnutrition, which is one of the leading causes of infant mortality in developing countries. Khare et al. (2017) designed a prediction model for malnutrition based on a machine learning approach, using the available features in the Indian Demographic and Health Survey (IDHS) dataset. Their findings suggest that this approach identifies some important features that had not been detected by the existing literature. Another example is the Child Growth Monitor app developed by the German NGO Welthungerhilfe, which identifies malnutrition in children using inbuilt infrared cameras for scanning and machine learning to correlate the scan with anthropometric measures (Welthungerhilfe 2018). The app was pre-tested in India and the results are promising. It may replace the manual measures of weight and height, which are costly, slow, and often inaccurate. Apps also offer targeted nutritional advice directly to households. Numerous nutrition apps already exist which monitor food intake and provide dietary recommendations to its users. One available feature of these 
apps, which is enabled through deep learning, is the tracking of macronutrient content by taking a photo of the meal that is about to be consumed. In the future, these apps may also be used for personalized dietary advice and tailored health messages in developing countries. In this way, smartphone apps can be a low-cost intervention for improving dietary quality and health even in remote areas with limited access to dieticians or health workers.

AI-enabled diagnostic tools could improve health services in remote areas (Wood et al. 2019). These technologies could support self-diagnosis or assist health workers. For example, researchers at Stanford University have trained an algorithm to diagnose skin cancer from images (Kubota 2017). The Israeli company Zebra Medical Vision is partnering with Indian authorities to roll out its AI-based medical imaging technology which can diagnose tuberculosis using chest Xrays (Zebra Medical Vision Team 2019). AI-technologies also enable a faster detection of emerging epidemics such as Ebola or Zika (Wood et al. 2019). It will be important to ensure that AI technologies are adapted to a wide range of people's characteristics. Research has shown that using training data from specific population groups may exclude some social groups (Gershgorn 2018). Machine learning requires large amounts of data which may not be easily available from the poor and marginalized who currently do not have access to health services. Moreover, well-trained human intermediaries would still be required to explain and build trust in diagnostic results. Importantly, diagnostic tools will only be useful if they are complemented with improved access to treatment for the poor.

Robots may help to improve access to and quality of surgical care. The Lancet Commission estimates that 9 out of 10 people in low- and middle-income countries do not have access to safe, affordable surgical and anaesthesia care (Meara et al. 2015). Only 6\% of the 313 million surgeries performed annually take place in the poorest countries (Meara et al. 2015). Robots are already being used to assist and thereby enhance the capability of surgeons to perform complex procedures. In the long-run, they could even be used to undertake surgery remotely. While it is still early days for such treatments, rapid advances in technological capacities will bring them closer within reach. China, for instance, is already experimenting with remotely operated robots to carry out orthopaedic surgery (Demaitre 2019). However, given that such procedures are costly, still rely on trained personnel on-site and require $5 \mathrm{G}$ networks, it may be a long time until they reach rural areas that still struggle to access even $3 G$ networks.

AI may also assist in humanitarian health crises by extracting valuable information for decision-making. Fernandez-Luque and Imran (2018) find that while there are many examples of the use of artificial intelligence in health crises, they are largely limited to outbreak detection while their application in low-income countries is underresearched. Capacities for data sharing and real-time analysis, combined with human and organizational aspects, are the main constraints to the use of $\mathrm{AI}$ in this area.

\section{Al-Assisted Financial Services}

A large share of the poor lack access to formal financial services such as banking, credit or insurance. In 2017, only one third of adults in rural Sub-Saharan Africa owned a bank account and only $5 \%$ held a loan from a formal financial institution (World Bank 2019). Access to insurance for small and medium sized enterprises in Africa, which could help them better manage risks and improve their risk profile vis-à-vis lenders, also remains limited. Similarly, only few smallholders in the region held crop insurance in 2016 (Hess and Hazell 2016). AI could in particular assist in facilitating access to credit and insurance for the poor, but there are also risks for the poor when $\mathrm{AI}$ is used to support discriminatory screening in credit approval procedures or predatory operations of "fintech" organizations (Hill and Kozup 2007; Variyar and Vignesh 2017).

Banks are often reluctant to provide loans to low-income households because they are unable to assess the risk of loan default. AI-based systems can assist in credit-scoring by using data collected by mobile phones, such as call-detail records, social network analytics techniques or credit and debit account information of customers (Óskarsdóttir et al. 2019), and combining them with agronomic, environmental, economic, and satellite data. The Kenyan company Apollo Agriculture, ${ }^{7}$ for instance, uses machine learning to analyse data about farmers collected by field agents and satellite imagery to create a profile of the farmers and evaluate their credit-worthiness. Loans are then disbursed via agro-dealers and also bundled with insurance in case of yield losses.

AI could also assist in the provision of insurance to a large number of dispersed, small-scale farmers and businesses by providing high-quality data, minimizing uncovered basis risk and lowering cost delivery mechanisms. In view of climate change and the related increase in weather risks, important areas are weather services and weather risk insurances building upon AI-enhanced weather observation and monitoring at pixel levels. ${ }^{8}$ For instance, index-based insurance using remote-sensing data has shown to be promising as a means of providing crop insurance in areas and to customers that were previously out of reach (De Leeuw et al. 2014; IFAD 2017). AI can also help to monitor or develop

\footnotetext{
${ }^{7} \mathrm{https}: / /$ www.apolloagriculture.com/

${ }^{8}$ Aerobotics (South Africa) is an example for machine learning on aerial imagery to identify problems in crop yields (World Wide Web Foundation 2017).
} 
efficient index-based insurance for pastoralists by predicting livestock mortality sufficiently in advance to ensure ex-ante asset protection insurance.

The provision of such services are greatly facilitated by mobile money services. The most prominent example in Africa is M-Pesa ( $\mathrm{M}$ is for mobile, "pesa" is Swahili for "money") which started in Kenya in 2007. M-Pesa allows people from all around the country, even in the most remote areas, to transfer money directly, saving considerable amounts of time and money. In 2018, just over $80 \%$ of the adult population of Kenya was registered (CA 2018). While M-Pesa is not AI-based, it facilitates recording even small business and farm performance and financial transactions including productivity, expenses, sales and revenues, thereby providing valuable information to build credit profiles. The data can also be used to inform other decisions, such as investments in roads, storage facilities for farmers or financial infrastructure.

\section{Al and Social Transfers}

In recent years, social protection programs including cash transfers to the poor, some of them implemented with certain conditions such as children's school participation, and labour-intensive public works programs (PWPs), have expanded in many countries. By combining different datasets, machine learning can contribute to increasing the efficiency of targeting social interventions and channeling humanitarian responses in the course of crises.

For instance, PWPs' benefits are sometimes obscured to such an extent that PWPs become deficient, e.g. when not targeting the intended beneficiaries or due to leakages related to corruption. The main objective of PWPs is to provide social protection to the working-age poor by transferring cash or in-kind to beneficiaries to protect households' consumption while at the same time promoting savings and investments in productive assets, the generation of public goods, and the provision of training to support rural transformation. AIbased tools can enable real-time monitoring by facilitating the collection, processing, management, validation, and dissemination of data for operations, accountability, and policy decision making. In the case of vast PWPs in India, the development of a management information system (MIS) to support program processes and structures ensured more reliable and on-time management of big data that comes from multiple sites and levels of program implementation, thus minimizing errors, frauds, and corruption (Subbarao et al. 2013).

AI-enabled welfare programmes have also attracted criticism (Alston 2019; Eubanks 2018). The UN Special Rapporteur on extreme poverty and human rights, Philip Alston, warns in a report to the UN General Assembly that algorithms used for targeting and enforcing social protection programs may lead to wrong decisions or discrimination, especially in the absence of data for certain societal groups. Moreover, the poor and marginalized with limited digital and technological capacities may find it difficult to interact with digital systems. Issues of data privacy may also arise, given that such systems rely on the collection and integration of large sets of personal data.

\section{Al/Robotics Effects for the Poor in Employment, Small Business, and Smallholder Farming}

Employment generation is a key policy priority for many African governments to create job and income opportunities for the 300 million young people who are projected to enter the labour market by 2030 (AfDB 2019). The impact of $\mathrm{AI} / \mathrm{R}$ on employment through the introduction of industrial automation and labour saving technologies is perhaps the most widely debated issue when it comes to distributional effects of these technologies. ${ }^{9}$ The main concern relates to the loss of jobs for low-skilled labour, which is of particular relevance to the poor. The capacity to work is the key asset of the poor, be it in the labour market or as small entrepreneurs in the service sector or small-scale farming.

Theoretically, this concern may be derived from the classical model designed by Arthur Lewis (1954; cf. Polany Levitt 2008). Lewis' model assumes an unlimited supply of unskilled labour while the opportunity cost of labour determines wages in the modern sector. More specifically, the model supposes a traditional working environment of peasants, artisanal producers, and domestic servants, which is subjected to population pressures. This situation in the traditional sector grants the modern sector "unlimited supplies" of labour, with wages exceeding the subsistence level only by a small margin. As the modern sector expands, employment and output, as well as the share of profits in national income, rise. At a certain point, the surplus labour from the traditional sector is exhausted, which leads to the wage rate increasing as productivity further rises.

Within the context of AI/R technologies, however, this so-called Lewis inflection point may no longer be reached in emerging economies if there were to evolve an unlimited "robot reserve army" which competes with the labour force of the poor (Schlogl and Sumner 2018). In adaption of the Lewis model of economic development, Schlogl and Sumner (2018) use a framework in which the potential for automation creates "unlimited supplies of artificial labor" particularly in the agri-

\footnotetext{
${ }^{9}$ See, for instance, Acemoglu and Restrepo (2017), Chiacchio et al. (2018), Frank et al. (2019), Korinek (2019), Korinek and Stiglitz (2017), also published in Agrawal et al. (2019), and Marin (2018).
} 
cultural and industrial sectors due to technological feasibility. This is likely to push labour into the service sector, leading to a further expansion of the already large and low-productive service-sector employment. Gries and Naudé (2018) assess these issues by incorporating AI-facilitated automation with modelling to allow for demand-side constraints and thereby finding less adverse effects for employment.

Acemoglu and Restrepo (2017) distinguish two potential employment effects of automation. First, robots may displace and thereby reduce the demand for labour (displacement effect). Through linkages within global value chains, workers in low-income countries may also be affected by robots in higher-income markets, which could reduce the need for outsourcing such jobs to low-wage countries overseas. As a result, low-skill, labour-intensive industrialization, as observed in many East Asian countries, may no longer be a promising development model. Second, robot use could increase the demand for labour either by reducing the cost of production which leads to industry expansion (price-productivity effect) or by increasing total output overall (scale-productivity effect).

The key question from a poverty and distributional perspective will be which jobs are replaced and which are generated. Policies should aim at providing social security measures for affected workers while investing in the development of the necessary skills to take advantage of newly created jobs. This is easier said than done, however, especially for the poor who often start from a very low level of education.

Small businesses can grow rapidly thanks to digital opportunities, expanding their boundaries and reshaping traditional production patterns. The rise of digital platform firms means that technological effects reach more people faster than ever before. Technology is changing the skills that employers seek. Ernst et al. (2018) point out that opportunities in terms of increases in productivity, including for developing countries, can ensue, given the vastly reduced costs of capital that some applications have demonstrated and the potential for productivity increases, especially among lowskilled workers. Makridakis (2017) argues that significant competitive advantages will accrue to those utilizing the Internet widely and willing to take entrepreneurial risks in order to turn innovative products/services into commercial success stories.

A large proportion of the poor live on small farms, particularly in Africa and South and East Asia. Digital technologies, services, and tools can offer many opportunities for smallholder farmers to make more informed decisions, and to increase productivity and incomes. Key benefits of digitalization include greater access to information and other services including finance, links to markets, a sustainable increase in productivity, and better informed policies. ${ }^{10}$ Examples are:

\footnotetext{
${ }^{10}$ A study on 81 countries revealed significant positive effects of an increase in ICTs adoption on agricultural productivity already at the
}

- Land ownership certification: In many developing countries, land rights are unclear and contested. Smartphones, cameras or drones, which can capture geospatial and topographical data-using, for example, Global Positioning Systems and global navigation satellite systems-are therefore useful tools for land mapping and land tenure programs. For instance, machine learning can be used to predict the boundaries of parcels based on common property boundary features. If this geospatial data and land transaction history is saved through blockchain technology, land registries could become extremely robust.

- Precision technologies: including big data, satellite imagery, sensors, robotics, drones, etc. ${ }^{11}$ For instance, in South Africa, the drone start-up Aerobotics is using drone technology and AI to assist farmers in optimizing their yields, thereby greatly contributing to cost reduction. In Kenya, AI and big data analytics provide useful information about farming trends and productivity based on data that is generated through soil analysis. Another AIassisted application is image recognition to diagnose plant diseases, offer information about treatments and to monitor the spread of diseases based on photos of the plant taken with a smartphone.

- Farm machinery: Tractors mounted with sensors and connected to mobile platforms allow users to remotely capture farm information related to soil, water, and crop conditions, to calibrate usage of inputs accordingly, and to monitor progress. Innovative models such as "uberization" of tractors and farm machinery, which make farm machinery available on rent and make mechanization more effective and affordable for the farmers, are gaining popularity in developing countries.

- Innovations in irrigation and energy: Solar-driven micro irrigation systems can help reduce energy costs and, when connected to the grid, allow farmers to benefit from selling generated surplus energy. AI/R complex systembased algorithms help to build efficient water systems for communal irrigation or optimization of water resources, distribution, and infrastructure planning, for instance.

- Access to information: AI-enabled digital services can enhance farmers' access to personalized information related to weather, soil health, market prices, and finance that is specifically adapted to their local context and information needs. This enables farmers to plan their farming activities, project the potential output and hence bargain for better prices. Through AI-based speech recognition, information can become accessible for farmers with low levels of literacy.

early stages of digitization (Torero and von Braun 2006; Lio and Liu 2006). Substantial progress has been made in this regard in the past decade.

${ }^{11}$ This section draws on Ganguly et al. (2017). 
- ICTs platforms connecting buyers and sellers: AI can improve the functioning of virtual market platform, e.g. to better match buyers and sellers, facilitate transactions or respond to customer queries. In addition, the data collected by e-commerce platforms can be analysed using AI tools in order to inform decision-making, for instance on which crops to plant depending on demand or price trends or on government investments in logistics infrastructure.

The challenge lies in the effectiveness of these technologies in addressing the field level issues and making these applications user friendly for poor farmers. Hence, the focus needs to be on integrating several of these applications in user-friendly platforms designed with in-built data interpretation and predetermined actions to equip users with end-toend solutions.

\section{Al/Robotics Links to Voice and Empowerment}

To the extent that AI/R take over functions that are currently provided by poor and marginalized people, these technologies may have adverse effects on their rights and entitlements, and - by extrapolation - their capacities to influence social and economic policies may suffer. However, if new AI/R functions were usable by or even come under the direct control of marginalized and poor people, these people might become more empowered. The latter direct effect will be more likely if collective actions by the poor are facilitating access at scale to specific AI/R applications, such as AI-facilitated land rights or R-facilitated drone technologies reducing hazardous work on farms. Yet, so far, there remain huge digital gaps between the rich and the poor, and it may remain the same in the field of AI/R applications, thus limiting direct benefits of $\mathrm{AI} / \mathrm{R}$ for the poor.

More impactful may be indirect effects of AI on voice and empowerment, given the weight of poor populations in political decision making, including elections or protest movements. In this regard, AI-based tools can both empower and disempower the poor (Polonski 2017; Savaget et al. 2019). Automated translation tools, for instance, can empower people by helping them to vote or be more informed about political processes. AI can also increase the transparency of government by analysing increasingly large volumes of open data which may otherwise be difficult to interpret, in particular for less educated readers. It can also be used to verify the accuracy of information and highlight articles or messages that contain misinformation. However, the same technologies can also be used to generate and spread false information and thereby manipulate public opinion (Shorey and Howard 2015).
At the same time, AI-enabled technologies risk reinforcing existing inequality. The World Wide Web Foundation (2017) emphasizes that “... AI present a tremendous set of opportunities and challenges to human well-being [but] there is also concern that AI programs and decision-making systems supported by AI may include human biases, leading to further discrimination and marginalization" (p. 3). Indeed, algorithms and neural networks are not neutral, but are shaped by the data used for training. Caliskan et al. (2017) show that machine learning can take on biases, for example with regard to race or gender when trained with standard textual data from the web. There are initiatives that aim to change this, such as the "Whose Knowledge?" initiative which defines itself as a "... global campaign to center the knowledge of marginalized communities ... on the internet." 12 They work particularly with women, people of colour, communities like Dalits in India, and others to create and improve related content.

Regarding privacy and access to information rights, the poor are particularly threatened because of their current lack of power and voice. New forms of regulating the digital economy are called for that ensure proper data protection and privacy, and help share the benefits of productivity growth through a combination of profit sharing, (digital) capital taxation, and a reduction in working time. Investments in skills need to be enhanced, and the enabling business environment strengthened to include the poorer and more vulnerable groups (World Bank 2017).

Another important dimension to consider is the impact of AI on human autonomy or agency as information provision and decision-making is handed over to seemingly intelligent machines (Pew Research Center 2018). This may be a particular concern for the poor and disadvantaged who often have limited access to alternative information sources.

\section{Policy Conclusions}

A broadly based policy agenda will be needed to include the poor and marginalized in opportunities of $\mathrm{AI} / \mathrm{R}$ and to shield them from discrimination and indirect adverse effects. Options for policy actions are presented in Fig. 2. For the areas of influence that were identified in Fig. 1, examples of possible actions to harness the potential of $\mathrm{AI} / \mathrm{R}$ for the poor are listed, including targeted $\mathrm{AI} / \mathrm{R}$ applications and supporting framework conditions. A number of cross-cutting policy actions are proposed:

Strengthen skills to develop and use AI/R technologies and enable the poor to take advantage of related employment opportunities. AI/R risks for employment and the poor call for investing in human capital in order to build the skills in

\footnotetext{
${ }^{12} \mathrm{https}: / /$ whoseknowledge.org/
} 

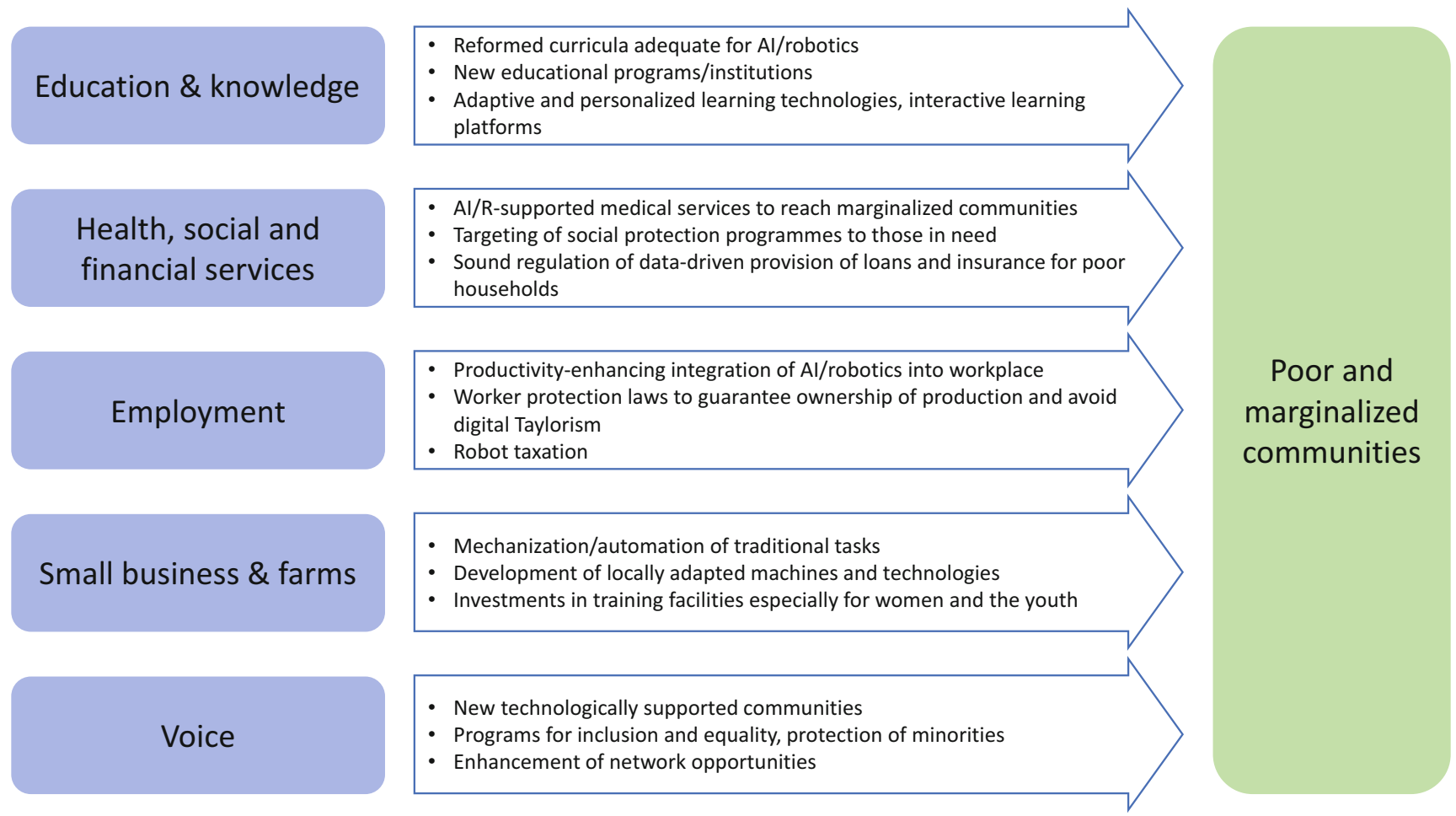

Fig. 2 Policy action options for pro-poor AI/R. Source: designed by authors

demand in the labour market. Indeed, skill development is perhaps the most important area of intervention to enhance benefits from $\mathrm{AI} / \mathrm{R}$. This needs to happen at various levels. Existing curricula need to be adapted, starting from school all the way to tertiary education. In addition, new education programs and institutions will be needed. One set of skills includes basic digital literacy of end-users, including intermediaries such as extension agents, agro-dealers or community leaders who could help cover the last mile to reach the poor and marginalized. Another set of skills include more advanced technical skills for the local development of $\mathrm{AI} / \mathrm{R}$ solution and the use of more sophisticated applications in business operations. These skills would allow local communities to take advantage of direct job and income opportunities related to AI/R applications. These are unlikely to benefit the poor and marginalized, however. It is therefore imperative to ensure that these groups have the necessary skills to benefit from jobs or income opportunities that may be indirectly created where $\mathrm{AI} / \mathrm{R}$ raises productivity and industrial output e.g. increased demand for raw materials or transport services.

Adapt AI/R solutions to the local context of the poor and marginalized. To ensure that $\mathrm{AI} / \mathrm{R}$ solutions also benefit the poor, their usability will be crucial. Interfaces need to be adapted so as to be accessible for users with low literacy levels and also match the technological capacities of devices commonly used by these groups. Dissemination strategies should take advantage of intermediaries to reach and assist these users. Similarly, the functions and content of related solutions need to be adapted to the needs of the poor. This includes the use of locally adapted models for AI applications that employ data from all societal groups to train algorithms, preventing any discriminations. Significant investments and efforts need to be made to collect such data.

Introduce safeguards to mitigate negative employment effects resulting from the introduction of AI/R. Realistically, the poor will find it difficult to benefit directly from many of the employment opportunities that could be generated by AI/R. Therefore, governments need to enhance social protection and extend it to all people in society, irrespective of the terms on which they work. This will enable the redistribution of the benefits of $\mathrm{AI} / \mathrm{R}$ and digitalization more generally. Taxation policy may provide a suitable avenue to address the distributional effects. Several countries are already taxing certain digital activities, among them some lower and lowermiddle income economies such as India, Kenya, Pakistan and Zimbabwe, while others are considering to follow suit (KPMG 2019). In addition, a "robot tax" (Delaney 2017), could be considered. Bruun and Duka (2018) suggest that the resulting tax revenue could be used to mitigate future 
technological unemployment through the introduction of a basic income scheme, accompanied by reforms in school curricula and retraining programs.

Implement supporting measures to increase the effectiveness of AI/R for the poor. On the one hand, more investments will be required to ensure that $\mathrm{AI} / \mathrm{R}$ applications can be used by and are useful for the poor. Several areas of intervention were already mentioned above, such as digital literacy, usability and data collection. Significant investments in the digital infrastructure will also be needed, e.g. to expand fast mobile networks into rural areas. In addition, complementary measures will be needed that support the implementation of $\mathrm{AI} / \mathrm{R}$ solutions, such as health workers that can assist in the use of $\mathrm{AI} / \mathrm{R}$-enabled health services or investments in the agriculture sector to support smallholders farmers e.g. by improving access to digital farming, financial services or markets. On the other hand, measures are required to support local start-ups in the development of pro-poor AI/R innovations, such as innovation hubs, usability labs, education or access to finance. The development of $\mathrm{AI} / \mathrm{R}$ technologies compatible to the needs of the poor needs to be on the agenda of social businesses and NGOs. In addition, more collaboration of $\mathrm{AI} / \mathrm{R}$ specialists with social scientists is required to arrive at pro-poor $\mathrm{AI} / \mathrm{R}$.

To conclude, there are opportunities and risks of $\mathrm{AI} / \mathrm{R}$ for the poor. AI/R are not neutral in terms of their poverty and distributional effects. Research on the distributional implications of $\mathrm{AI} / \mathrm{R}$ is currently not being paid sufficient attention. The AI/R opportunities are mainly expected to benefit richer segments of society but as this situation is changing, for instance with jobs lost in employment in the banking sector, the attention to the distributional effects of $\mathrm{AI} / \mathrm{R}$ will increase. Empirical scenarios and modelling analyses are needed in the different national and societal contexts to better understand the components in the emerging technological and institutional AI/R innovations and identify how they may shape the livelihoods of poor households and communities. Fascination with AI/R must not divert attention from poverty and marginalization. It is important to explicitly pay attention to the outcomes for the poor, and focus on inclusive artificial intelligence and robotics.

\section{References}

Acemoglu, D., \& Restrepo, P. (2017). Robots and jobs: Evidence from US labor markets. NBER working paper no. 23285. Cambridge: National Bureau of Economic Research.

AfDB. (2019). African economic outlook 2019. Abidjan: African Development Bank.

Agrawal, A., Gans, J., \& Goldfarb, A. (2019). The economics of artificial intelligence. Cambridge and Chicago: National Bureau of Economic Research and University of Chicago Press.

Alston, P. (2019). Report of the special rapporteur on extreme poverty and human rights. A/74/493. New York: UN General Assembly.
Blumenstock, J., \& Cadamuro, G. (2015). Predicting poverty and wealth from mobile phone metadata. Science, 350, 1073-1076.

Bonafilia, D., Gill, J., Kirsanov, D., \& Sundram, J. (2019). Mapping for humanitarian aid and development with weakly and semi-supervised learning. Facebook Artificial Intelligence Blog, 9 April. Retrieved November 11, 2019, from https://ai.facebook.com/blog/mappingthe-world-to-help-aid-workers-with-weakly-semi-supervisedlearning/.

BRCK. (n.d.). Hardware, software and connectivity tools to enable learning. Retrieved November 15, 2019, from https:// www.brck.com/education/.

Bruun, E. P. G., \& Duka, A. (2018). Artificial intelligence, jobs and the future of work: Racing with the machines. Basic Income Studies, 13(2). https://doi.org/10.1515/bis-2018-0018.

Birhane, A., \& van Dijk J. (2020). Robot Rights? Let's Talk about Human Welfare Instead. Proceedings of the AAAI/ACM Conference on AI, Ethics, and Society. New York: Association for Computing Machinery, 207-213. https://doi.org/10.1145/3375627.3375855

CA. (2018). Second quarter sector statistics report for the financial year 2018/2019. Nairobi: Communications Authority of Kenya.

Caliskan, A., Bryson, J. J., \& Narayanan, A. (2017). Semantics derived automatically from language corpora contain human-like biases. Science, 356(6334), 183-186. https://doi.org/10.1126/science.aal4230.

Chiacchio, F., Petropoulos, G., \& Pichler, D. (2018). The impact of industrial robots on EU employment and wages: A local labour market approach. Working paper 25186(2). Brussels: Bruegl.

Ciechanover, A. (2019). The revolution of personalized medicine-Are we going to cure all diseases and at what price? Concept Note of the Pontifical Academy of Sciences-summit on the revolution of personalized medicine, Vatican, 8-9 April 2019.

De Leeuw, J., Vrieling, A., Shee, A., Atzberger, C., Hadgu, K. M., Birandar, C. M., Keah, H., \& Turvey, C. (2014). The potential and uptake of remote sensing in insurance: A review. Remote Sensing, 6(11), 10888-10912. https://doi.org/10.3390/rs61110888.

Delaney, K. J. (2017). The robot that takes your job should pay taxes, says Bill Gates. Quartz, 17 February. Retrieved December 18, 2019, from https://qz.com/911968/bill-gates-the-robot-thattakes-your-job-should-pay-taxes/.

Demaitre, E. (2019). Remote surgery using robots advances with $5 G$ tests in China. The Robot Report, 9 September. Retrieved January 6, 2020, from https://www.therobotreport.com/remote-surgery-viarobots-advances-china-5g-tests/.

Du Boulay, B., Poulovassilis, A., Holmes, W., \& Mavrikis, M. (2018). Artificial intelligence and big data to close the achievement gap. In R. Luckin (Ed.), Enhancing learning and teaching with technology: What the research says (pp. 256-285). London: UCL IoE Press.

Ernst, E., Merola, R., \& Samaan, D. (2018). The economics of artificial intelligence: Implications for the future of work. ILO future of work research paper series. Geneva: International Labor Organization.

Eubanks, V. (2018). Automating inequality: How high-tech tools profile, police, and punish the poor. New York: St Martin's Press.

Fernandez-Luque, L., \& Imran, M. (2018). Humanitarian health computing using artificial intelligence and social media: A narrative literature review. International Journal of Medical Informatics, 114, 136-142. https://doi.org/10.1016/j.ijmedinf.2018.01.015.

Frank, M. R., et al. (2019). Toward understanding the impact of artificial intelligence on labor. Proceedings of the National Academy of Sciences, 116(14), 6531-6539. https://doi.org/10.1073/ pnas.1900949116.

Ganguly, K., Gulati, A., \& von Braun, J. (2017). Innovations spearheading the next transformations in India 's agriculture. ZEF working paper 159. Bonn: Center for Development Research, University of Bonn. https://doi.org/10.22004/ag.econ.259006.

Gershgorn, D. (2018). If AI is going to be the world's doctor, it needs better textbooks. Available via prescription AI: The algorithm will see you now. Quartz, 6 September. Retrieved Novem- 
ber 11, 2019, fromhttps://qz.com/1367177/if-ai-is-going-to-be-theworlds-doctor-it-needs-better-textbooks/.

Google Cloud. (2019). AI \& machine learning products: Cloud speechto-text: Language support. Available via Google Cloud. Retrieved November 15, 2019, from https://cloud.google.com/speech-to-text/ docs/languages.

Gries, T., \& Naudé, W. (2018). Artificial intelligence, jobs, inequality and productivity: Does aggregate demand matter? IZA DP no. 12005. Bonn: Institute of Labor Economics.

GSMA. (2018). The mobile gender gap report 2018. London: GSM Association.

Hess, U., \& Hazell, P. (2016). Innovations and emerging trends in agricultural insurance: How can we transfer natural risks out of rural livelihoods to empower and protect people? Bonn and Eschborn: Deutsche Gesellschaft für Internationale Zusammenarbeit (GIZ).

Hill, R. P., \& Kozup, J. C. (2007). Consumer experiences with predatory lending practices. Journal of Consumer Affairs, 41(1), $29-46$.

IFAD. (2017). Remote sensing for index insurance: An overview of findings and lessons learned for smallholder agriculture. Rome: International Fund of Agricultural Development.

ITU. (2018). Focus group on "Artificial Intelligence for Health". Retrieved November 15, 2019, from https://www.itu.int/en/ITU-T/ focusgroups/ai4h/Pages/default.aspx.

ITU. (2019). ICT Statistics home page. Retrieved November 15, 2019, from https://www.itu.int/en/ITU-D/Statistics/Pages/default.aspx.

Jean, N., Burke, M., Xie, M., Davis, W. M., Lobell, D. B., \& Ermon, S. (2016). Combining satellite imagery and machine learning to predict poverty. Science, 353(6301), 790-794. https://doi.org/10.1126/ science.aaf7894.

Kemp, S. (2018). Global digital report 2018. Retrieved November 15, 2019, from https://wearesocial.com/blog/2018/01/global-digitalreport-2018.

Khare, S., Kavyashree, S., Gupta, D., \& Jyotishi, A. (2017). Investigation of nutritional status of children based on machine learning techniques using Indian demographic and health survey data. Procedia Computer Science, 115, 338-349. https://doi.org/10.1016/ j.procs.2017.09.087.

Korinek, A. (2019). Labor in the age of automation and artificial antelligence. Econfip Research Brief, Economists for Exclusive Prosperity.

Korinek, A., \& Stiglitz, J. E. (2017). Artificial intelligence and its implications for income distribution and unemployment. NBER working paper 24174. Cambridge: National Bureau of Economic Research.

KPMG. (2019). Taxation of the digitalized economy. Birmingham: KPMG LLP.

Kubota, T. (2017). Artificial intelligence used to identify skin cancer. Standford News, 3 May. Retrieved November 15, 2019, from https:/ /news.stanford.edu/2017/01/25/artificial-intelligence-used-identifyskin-cancer/.

Lewis, W. A. (1954). Economic development with unlimited supplies of labour. The Manchester School of Economic and Social Studies, 22(2), 139-191. https://doi.org/10.1111/j.14679957.1954.tb00021.x.

Lio, M., \& Liu, M. (2006). ICT and agricultural productivity: Evidence from cross-country data. Agricultural Economics, 34(3), 221-228. https://doi.org/10.1111/j.1574-0864.2006.00120.x.

Makridakis, S. (2017). The forthcoming artificial intelligence (AI) revolution: Its impact on society and firms. Futures, 90, 46-60. https:// doi.org/10.1016/j.futures.2017.03.006.

Marin, D. (2018). Global value chains, the rise of the robots and human capital. Wirtschaftsdienst, 98(1), 46-49. https://doi.org/10.1007/ s10273-018-2276-9.

McKetta, I. (2018). The world's Internet in 2018: Faster, modernizing and always on, Speedtest, 10 December. Retrieved November 15, 2019, from https://www.speedtest.net/insights/blog/2018internet-speeds-global.
Meara, J. G., Leather, A. J. M., Hagander, L., Alkire, B. C., Alonso, N., Ameh, E. A., Bickler, S. W., Conteh, L., Dare, A. J., Davies, J., Mérisier, E. D., El-Halabi, S., Farmer, P. E., Gawande, A., Gillies, R., Greenberg, S. L. M., Grimes, C. E., Gruen, R. L., Ismail, E. A., Kamara, T. B., Lavy, C., Lundeg, G., Mkandawire, N. C., Raykar, N. P., Riesel, J. N., Rodas, E., Rose, J., Roy, N., Shrime, M. G., Sullivan, R., Verguet, S., Watters, D., Weiser, T. G., Wilson, I. H., Yamey, G., \& Yip, W. (2015). Global surgery 2030: Evidence and solutions for achieving health, welfare, and economic development. Lancet, 386, 569-624. https://doi.org/10.1016/S0140-6736(15)60160-X.

Mirza, A. H. (2018). Poverty data model as decision tools in planning policy development. Sci J Informatics, 5(1), 39. https://doi.org/ 10.15294/sji.v5i1.14022.

Mussa, E. (2018). Long-term effects of childhood work on human capital formation, migration decisions, and earnings in rural Ethiopia. Doctoral Thesis, University of Bonn, Bonn.

Nye, B. D. (2015). Intelligent tutoring systems by and for the developing world: A review of trends and approaches for educational technology in a global context. International Journal of Artificial Intelligence in Education, 25(2), 177-203. https://doi.org/10.1007/s40593-0140028-6.

Óskarsdóttir, M., Bravo, C., Sarraute, C., Vanthienen, J., \& Baesens, B. (2019). The value of big data for credit scoring: Enhancing financial inclusion using mobile phone data and social network analytics. Applied Soft Computing, 74, 26-39. https://doi.org/10.1016/ j.asoc.2018.10.004.

Pew Research Center. (2018). Artificial intelligence and the future of humans. Washington, DC: Pew Research Center.

Polany Levitt, K. (2008). W. Arthur Lewis: Pioneer of development economics. UN Chronicle, XLV(1). Retrieved November 15, 2019, from https://unchronicle.un.org/article/w-arthur-lewispioneer-development-economics.

Polonski, V. (2017). How artificial intelligence conquered democracy. The Conversation, 8 August, Retrieved December 18, 2019, from https://theconversation.com/how-artificial-intelligenceconquered-democracy-77675.

Savaget, P., Chiarini, R., \& Evans, S. (2019). Empowering political participation through artificial intelligence. Science and Public Policy, 46(3), 369-380. https://doi.org/10.1093/scipol/scy064.

Schlogl, L., \& Sumner, A. (2018). The rise of the robot reserve army: Automation and the future of economic development, work, and wages in developing countries. Working paper 487. London: Center for Global Development.

Shorey, S., \& Howard, P. N. (2015). Automation, big data, and politics: A research review. International Journal of Communication, 10, $5032-5055$.

Singh, I. (2019). Facebook's highly-accurate Africa population maps are available for free download. GEO NEWS, 23 April. Retrieved November 11, 2019, from https://geoawesomeness.com/facebookshighly-accurate-africa-population-maps-are-available-for-freedownload/.

Smith-Clarke, C., Mashhadi, A., \& Capra, L. (2014). Poverty on the cheap: Estimating poverty maps using aggregated mobile communication networks. In R. Grinter, T. Rodden, \& P. Aoki (Eds.), Proc. of the SIGCHI conference on human factors in computing systems (pp. 511-520). New York: ACM.

Soto, V., Frias-Martinez, V., Virseda, J., \& Frias-Martinez, E. (2011). Prediction of socioeconomic levels using cell phone records. In J. A. Konstan, R. Conejo, J. L. Marzo, \& N. Oliver (Eds.), User modeling, adaption and personalization (pp. 377-388). Heidelberg: Springer.

SPEEDTEST. (n.d.). Speedtest Global Index. Retrieved November 15, 2019, from https://www.speedtest.net/global-index.

Stark, O., \& Bloom, D. E. (1985). The new economics of labor migration. The American Economic Review, 75(2), 173-178. http:// www.jstor.org/stable/1805591. 
Steele, J. E., Sundsøy, P. R., Pezzulo, C., et al. (2017). Mapping poverty using mobile phone and satellite data. Journal of the Royal Society Interface, 14(127), 20160690. https://doi.org/10.1098/rsif.2016.0690.

Subbarao, K., del Ninno, C., Andrews, C., \& Rodríguez-Alas, C. (2013). Public works as a safety net: Design, evidence, and implementation. Washington D.C: The World Bank.

Sundsøy, P., Bjelland, J., Reme, B. A., et al. (2016). Deep learning applied to mobile phone data for individual income classification. In A. Petrillo, A. Nikkhah, \& E. P. Edward (Eds.), Proceedings of the 2016 international conference on artificial intelligence: Technologies and applications. Amsterdam: Atlantic Press.

Torero, M., \& von Braun, J. (Eds.). (2006). Information and communication technology for development and poverty reduction: The potential of telecommunications. Baltimore: Johns Hopkins University Press.

Variyar, M., \& Vignesh, J. (2017). The new lending game, postdemonetisation, ET Tech, 6 January. Retrieved November 12, 2019, from https://tech.economictimes.indiatimes.com/news/technology/ the-new-lending-game-post-demonetisation/56367457.

von Braun, J. (2018). Rural girls: Equal partners on the path to employment. The Chicago Council. Retrieved November 11, 2019, from https://digital.thechicagocouncil.org/girls-rural-economies2018-report/von-braun-151YF-25398G.html.

von Braun, J. (2019). AI and robotics implications for the poor. ZEF working paper 188. Bonn: Center for Development Research, University of Bonn. https://doi.org/10.2139/ssrn.3497591.

von Braun, J., \& Gatzweiler, F. (Eds.). (2014). Marginality-Addressing the nexus of poverty, exclusion and ecology. Dordrecht: Springer. https://doi.org/10.1007/978-94-007-7061-4.
Welthungerhilfe. (2018). Child growth monitor app detects hunger. Retrieved November 11, 2019, from https:// childgrowthmonitor.org/ and Welthungerhilfe 20.03.2018 | Blog at https://www.welthungerhilfe.org/news/latest-articles/child-growthmonitor-mobile-app-detects-hunger/.

Wood, C. S., Thomas, M. R., Budd, J., et al. (2019). Taking connected mobile-health diagnostics of infectious diseases to the field. Nature, 566, 467-474. https://doi.org/10.1038/s41586-019-0956-2.

World Bank. (2017). G20 NOTE: Technology and jobs in the developing world. Retrieved November 11, 2019, from https:// www.ilo.org/wcmsp5/groups/public/\%2D\%2D-europe/\%2D\%2Dro-geneva/\%2D\%2D-ilo-berlin/documents/genericdocument/ wcms_556987.pdf.

World Bank. (2018). Poverty and shared prosperity 2018: Piecing together the poverty puzzle. http://hdl.handle.net/10986/30418

World Bank. (2019). The Global Findex Database 2017: Measuring financial inclusion and the Fintech Revolution, doi: https://doi.org/ 10.1596/978-1-4648-1259-0.

World Wide Web Foundation. (2017). Artificial intelligence: Starting the policy dialogue in Africa. Retrieved February 25, 2019, from https://webfoundation.org/research/artificial-intelligence-startingthe-policy-dialogue-in-africa/.

Zebra Medical Vision Team. (2019). From a dream to reality. Transforming India's healthcare. Zebra Medical Vision Blog, 12 September.https://zebramedblog.wordpress.com/2019/09/12/ transforming-indias-healthcare.

Zurutuza, N. (2018). Information poverty and algorithmic equity: Bringing advances in AI to the most vulnerable. ITU News, 2 May. Retrieved November 15, 2019, from https://news.itu.int/ information-poverty-and-algorithmic-equity-bringing-advances-inai-to-the-most-vulnerable/.

Open Access This chapter is licensed under the terms of the Creative Commons Attribution 4.0 International License (http://creativecommons. org/licenses/by/4.0/), which permits use, sharing, adaptation, distribution and reproduction in any medium or format, as long as you give appropriate credit to the original author(s) and the source, provide a link to the Creative Commons license and indicate if changes were made.

The images or other third party material in this chapter are included in the chapter's Creative Commons license, unless indicated otherwise in a credit line to the material. If material is not included in the chapter's Creative Commons license and your intended use is not permitted by statutory regulation or exceeds the permitted use, you will need to obtain permission directly from the copyright holder.

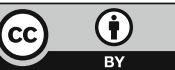

